\title{
Organization of Controlling the Intellectual Potential of Company Personnel
}

\author{
Aliya Z. Gafiyatullina ${ }^{1}$, Tatyana V. Nikonova ${ }^{2}$, Sergey G. Vagin ${ }^{3}$, Regina R. Kharisova ${ }^{4}$, Elena I. Pavlova ${ }^{5}$, Ramil \\ R. Khayrutdinov ${ }^{6} \&$ Izida I. Ishmuradova ${ }^{6}$ \\ ${ }^{1}$ Open Joint Stock Company Tatneft, Almetyevsk, Russia \\ ${ }^{2}$ Volga Region State Academy of Physical Culture, Sport and Tourism, Kazan, Russia \\ ${ }^{3}$ Samara State Economic University, Samara, Russia \\ ${ }^{4}$ Kazan State University of Architecture and Engineering, Kazan, Russia \\ ${ }^{5}$ National Research University "Moscow Power Engineering Institute", Moscow, Russia \\ ${ }^{6}$ Kazan (Volga region) Federal University, Kazan, Russia \\ Correspondence: Aliya Z. Gafiyatullina, Regulatory Research Station, Open Joint Stock Company Tatneft, \\ Mardzhani Street, 82, Almetyevsk, Tatarstan, 423458, Russia. E-mail: otiz_tn@tatneft.ru
}

Received: December 29, 2014

doi:10.5539/res.v7n4p13
Accepted: January 22, 2015 Online Published: February 11, 2015

URL: http://dx.doi.org/10.5539/res.v7n4p13

\begin{abstract}
The article aims to develop a structural model of controlling as a modern concept of human resources management in achieving strategic and operational objectives of the corporation and in developing the intellectual potential of employees. The process approach is defined as the basic approach to the study of this problem, producing the continuous improvement and development of employees' intellectual potential. The developed system of controlling, providing an estimate of the corporation personnel intellectual potential, reveals the reserves of the personnel performance optimization, of the incentives and growth measures. The article submissions may be useful in practical terms for executives of the corporation, personnel officers in developing the strategy and organizing the personnel management system of the enterprise.
\end{abstract}

Keywords: personnel, controlling, management, intellectual potential, the algorithm

\section{Introduction}

\subsection{Background}

The objectives of the large industrial associations are the stabilization and business solvency growth while determining the mechanisms of the strategy development and the arrangements of the entities' effective interaction (Ansoff, 2009; Gumerov, 2015; Masalimova, 2014). In modern conditions external economic globalization tendencies as well as and companies capitals aggregation, the issues related to improving effectiveness of strategic planning within major industrial clusters, where material and human resources concentration is high, become urgent (Webster, 2010; Pauli, 2009; Volovikov, Rebrova, 2010; Fayzullina, 2007; Shaidullina, 2012; Fayzullina \& Mukhametzyanova-Duggal, 2015).

The human's role, requirements to the workforce and to the professional training of industrial enterprise personnel are substantially changing in the present conditions of economic development (Milner, 2008; Muhamedyarov, 2008).

Understanding controlling as a concept of modern management, which emerged at the intersection of economic analysis, planning, administrative accounting and management, transfers the organization management to a whole new level, when integrating, coordinating and directing the activities of the organization to achieve its operational and strategic objectives (Danilochkina et al., 2006; Karminsky et al., 2005). In this regard it seems appropriate to apply to the quality management tools which efficiency has already been confirmed by domestic and foreign practices (Deming, 2011; Glischev, 2009; Gorbashko, 2008; Levina et al, 2015). Managing the development of company personnel turns out to be closely related with the development of controlling, as well, as the basis of measurement of resources, costs and benefits, and of all the activities of the organization as a whole (Shigahyev, 2008). Formation of a controlling system in HR management of a company will ensure 
coordinating activities of the departments, divisions and intellectual potential of the corporate employees, planning, budgeting for personnel costs.

\subsection{Status of a Problem}

Theoretical foundations and the issues on the practical implementation of controlling as the management concept are the research subjects of a number of domestic (Bezdidko, 2002; Petrenko, 2005; Falco, Nosov, 2005, etc.) and foreign scientists (Mann, 1995; Meyer, 2005; Follmut, 2005, etc.). Personnel controlling has been studied to a lesser extent, general issues on personnel management and on controlling personnel are considered in the works of Kaplan and Norton, 2005; Mikhailova, 2008 et al.

Methodology in current market conditions challenge efficiency, models design, determination of the planning and controlling tools in the industrial corporations activities, which will allow to employ their inherent resource potential, absolute and relative competitive advantages (Porter, 1993; Fathutdinov, 2008). The person's labor management should be directed on the organization of such conditions that: become the condition for person's self-actualization in professional activities; integrate the organization's goals and objectives of the employee; become a factor of increasing the organization's economic efficiency. (Egorshin, 2011; Bukhalkov, 2005; Mahankova, 2010; Noskova, 2010; Bovin et al, 2009; Lavrentiev \& Sharina, 2010).

\subsection{The Research Hypothesis}

The analysis of the theoretical and practical developments in the aspect of the problem showed that the issues related to the management require deeper research associated with the development of algorithms, performance indicators and implementation in enterprises, which enables us to determine the hypothesis: personnel controlling is an economic tool to increase company profits.

\section{Materials and Methods}

\subsection{Objective and Subject of the Research}

Objective: to develop and test the effectiveness of the personnel controlling algorithm in the enterprise in real conditions.

The research was conducted on the basis of an oil company JSC "Tatneft". The functioning specificity of the JSC "Tatneft" enterprise is that it is a large, mainstay enterprise, makes a significant contribution to the development of the region (Tatarstan, Russian Federation), and operates in the conditions of social market economy formation, and that is why the organization and management of the intellectual potential of the personnel has strategic importance both in the personal and social aspects.

\subsection{Methodology to Evaluate the Integral Index of Intellectual Potential of the Company Employees}

For the calculation of the integral index of the employees' intellectual potential it is necessary to determine the ranks and weight values for each of the three indices (BOF technique, Bystrov, 2008) included in its composition (real, educational and scientific-research).

1) Scientific-research capacity is the characteristics of research competence, creativity of a personality (rank 1 , weight 1 , normalized coefficient $\mathrm{C} 1=0.17$ ).

2) The educational potential is the qualitative characteristics of the intellectual potential, shows the contribution of education to the intellectual capacity (rank 2 , weight $1 / 2$, the normalized coefficient $\mathrm{C} 2=0.33$ ).

3) The real potential, i.e., the quantitative characteristics of the intellectual potential (rank 1 , weight $1 / 3$, the normalized coefficient $\mathrm{C} 3=0.5$ ).

The integral index of the intellectual potential of the company personnel is estimated according to the formula:

$\mathrm{IIIPP}=\mathrm{C} 1 * \mathrm{RP}+\mathrm{C} 2 * \mathrm{EP}+\mathrm{C} 3 * \mathrm{SRCI}$

where RP is the real potential index; EP is the educational potential index; SRCI is the scientific-research capacity index.

\section{Results}

\subsection{Stages of the Intellectual Potential Development of the Industrial Enterprise Personnel}

The intellectual potential of the personnel reflects the level of education, professionalism, skill level, experience, innovation culture of the workers, as well as their creativity and the ability to thought process and self-development, underpins the effective operation of any organization and is a source of labor productivity growth. 
Currently, there is a considerable gap between the need for innovative enterprise development and the necessary personnel intellectual potential for this, which is in the lack of development strategy and investing in staff.

Based on the underlying factors for each of the employees, on his/her personal qualities and aspirations, the development stages of the intellectual potential of the corporation personnel can be represented as a diagram (Fig. 1.)

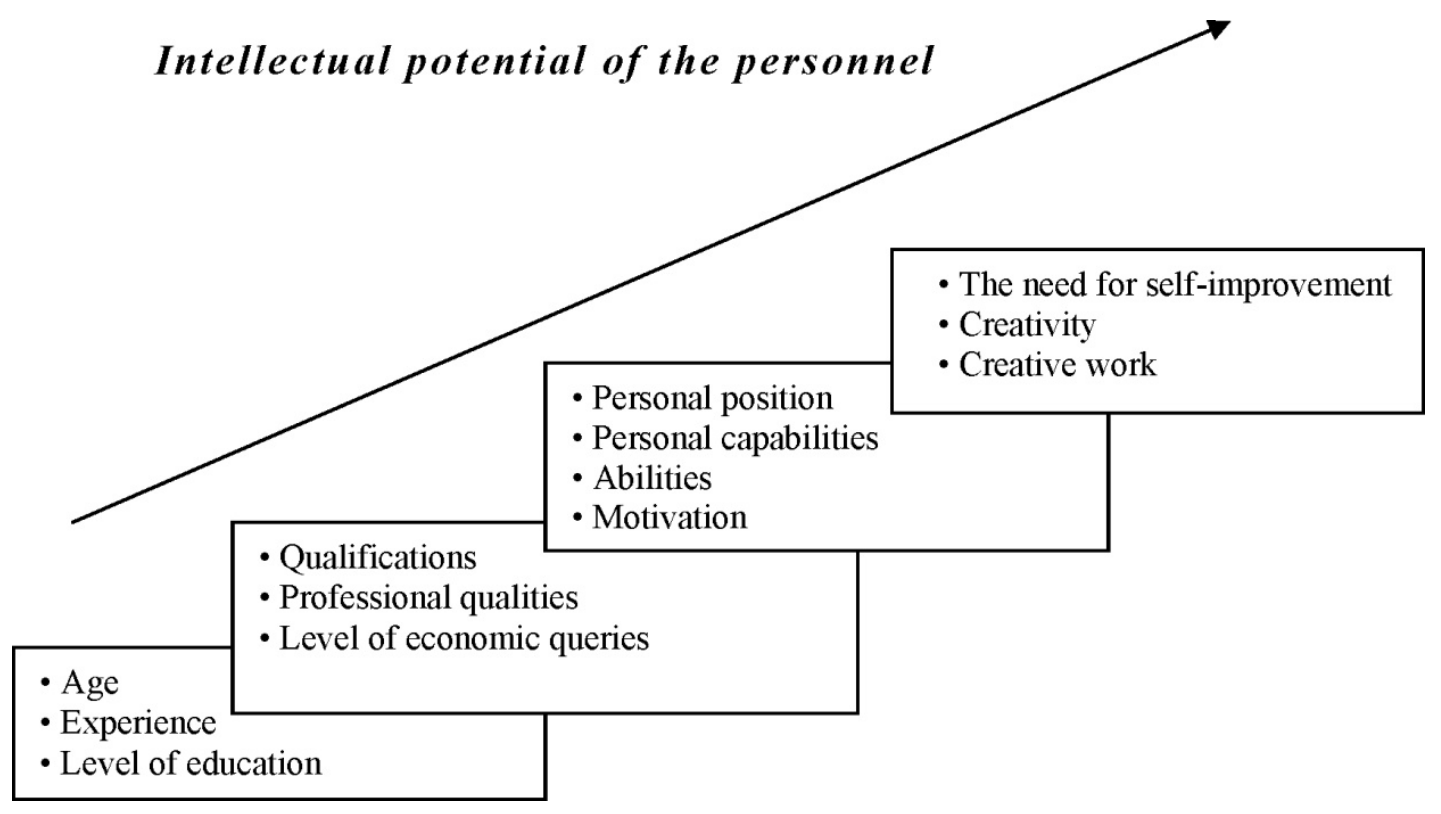

Figure 1. Stages of the intellectual potential development of the corporation personnel

Development according to the represented vector requires management decision-making on the basis of investment, including the methods of formation, maintenance, development and evaluation of staffing at each performance stage. The accumulation of intellectual potential of the personnel is based on the requirements of continuous improvement, the development of effective systems for additional training, the implementation of policies to increase the motivation and incentives.

\subsection{Defining the Objectives of Controlling the Intellectual Potential of the Company Personnel}

Controlling the intellectual potential of the personnel from the theoretical point of view is the concept and the basis of developing strategic planning of the personnel intellectual potential management, and from the practical one it is the system dynamic tools performing support of management decision making.

Objectives of controlling the intellectual potential of the personnel:

- Construction of a system of strategic and operational performance targets of the personnel intellectual potential;

- The use of control mechanisms to ensure the coordinated work of the staff towards the set objectives;

- Investigation of alternative options for achieving the objectives, rationale for choosing the optimal variant;

- Coordination of structural divisions, departments, and employees of the company, planning, budgeting;

- Analysis of the intellectual potential of the personnel, the rationale for implementing corrective actions;

- Evaluation of the effectiveness and feasibility of investment projects and tactical management decisions in the area of the personnel intellectual potential management.

\subsection{The Algorithm for Controlling the Development of the Company Personnel Intellectual Potential}

The authors developed an algorithm for controlling the intellectual potential of the corporation personnel (Fig. 2.).

The corporation personnel intellectual potential controlling focuses on the establishment of values corridors (planned state), determining the appropriateness of the actual implementation values, variance analysis and management decision making on this basis to improve the implementation effectiveness of the personnel potential and the personnel policy in general. Analysis of the divisions' indicators, of the company as a whole in 
the dynamics, comparison with the activities of companies within similar scope will provide information about the level of implementation of the goals before the intellectual potential of the personnel, the appropriateness of the expenditures for the employees, the consequences of the efficiency effects in the introduced technologies.

The developed algorithm was the basis for the organization of the personnel management system of the enterprise. Let's track the effectiveness of this system and the dynamics of the integral index of the JSC "Tatneft" company personnel intellectual potential (Table 1).

Table 1. Calculation of the integral index of the JSC "Tatneft" personnel intellectual potential (IPP)

\begin{tabular}{|c|c|c|c|c|}
\hline Indicators & 2011 & 2012 & 2013 & Weight coefficients \\
\hline Number of IPP, persons & 11830 & 9911 & 9100 & 0.17 \\
\hline Number of trained, persons & 5938 & 6046 & 7566 & 0.33 \\
\hline $\begin{array}{l}\text { Number of rationalization } \\
\text { proposals, utility models, } \\
\text { inventions, pieces. }\end{array}$ & 5938.5 & 6046 & 7566 & 0.5 \\
\hline $\begin{array}{l}\text { Personnel intellectual } \\
\text { potential (IPP) }\end{array}$ & 6939.89 & 6703.1 & 7826.8 & \\
\hline
\end{tabular}




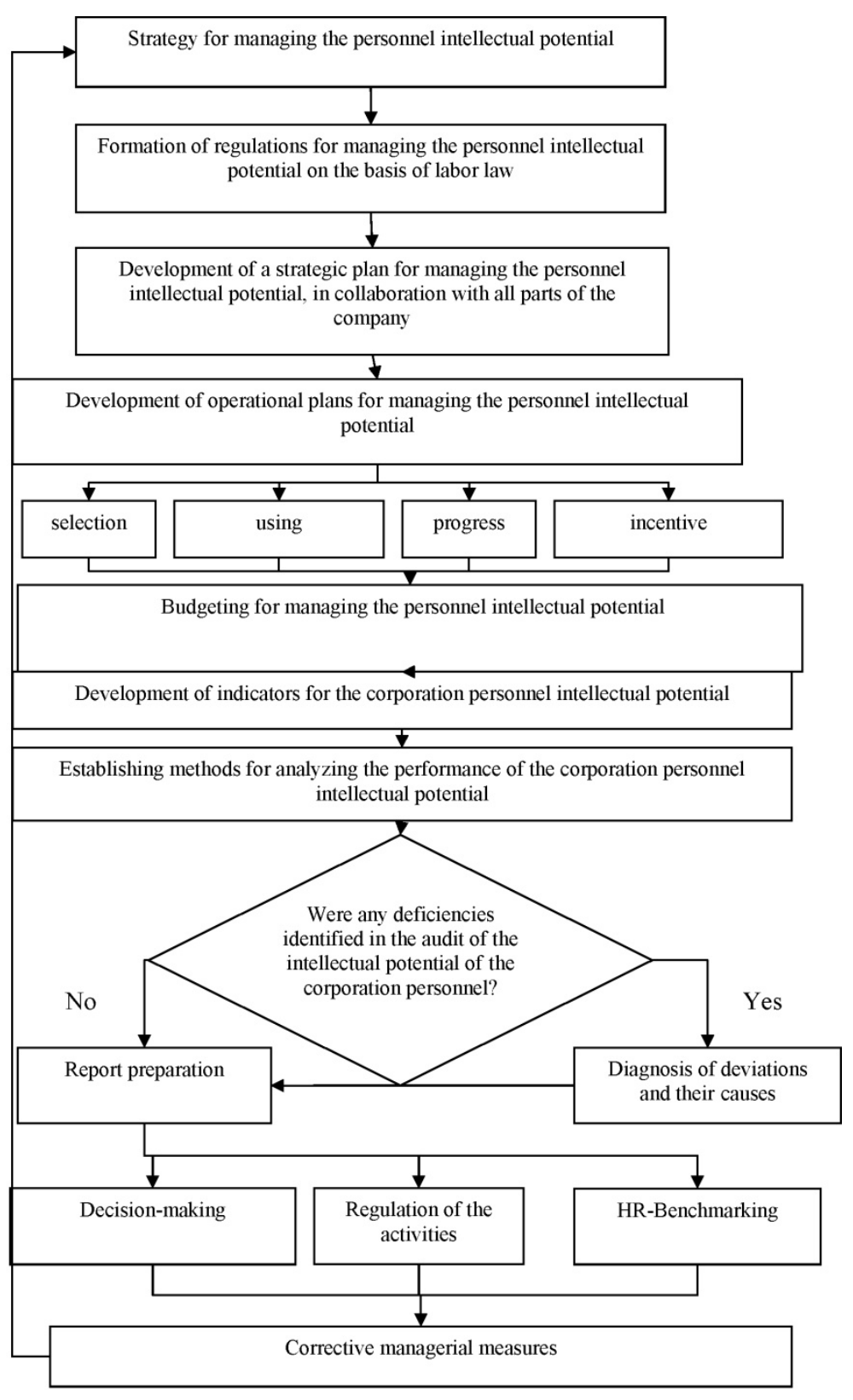

Figure 2. The algorithm for controlling the intellectual potential of the enterprise personnel

\subsection{Implementing the Elements of Controlling the Intellectual Potential of JSC "Tatneft" Personnel}

From the table it is seen that according to the results of controlling, significant staff reductions were conducted, which constitutes the intellectual potential of the company, leaving those employees whose development indicators were considered the best. In this case the integral IPP index has a clear upward trend, which indicates the effectiveness of the implemented controlling system in the personnel management, the optimization of the enterprise funds use.

\section{Discussions}

Controlling the intellectual potential of the corporation personnel focuses on the establishment of values corridors (planned state), determining the appropriateness of the actual implementation parameters values, variance analysis and on this basis making management decisions to improve the effectiveness of the personnel potential implementation and personnel policy in general. Analysis of the divisions' indicators dynamics, of the company as a whole in the dynamics, comparison with companies within similar scope of activities will provide 
information about the level of implementation of the goals before the intellectual potential of the personnel, the appropriateness of the expenditures for employees, the consequences of the efficiency effects in the introduced intelligent technologies.

\section{Conclusions}

Managing the intellectual potential of personnel according to the results of the controlling on the basis of the presented algorithm will ensure objectivity and transparency of administrative decisions, the possibility of investments in the development of the corporation personnel intellectual potential, and, ultimately, will maximize the payoff from the personnel.

\section{Acknowledgments}

The authors thank all participants of this study for their kind cooperation.

\section{References}

Ansoff, I. (2009). Strategic management (p. 344). St. Petersburg: Piter.

Bezdidko, Y. A. (2002). Basics of controlling (p. 25). Moscow: March Publisher.

Bovin, A. A. et al. (2009). Managing Innovation in Organizations. Moscow: Publishing House "Omega-L".

Bukhalkov, M. I. (2005). Personnel management: The development of labor potential (p. 192). Moscow: INFRA-M Publisher.

Bystrov, O. F. (2007). Investment ratings complex economic systems: Theory, technology calculation, practice (p. 218). Moscow: MGOU Publisher.

Danilochkina, N. E. et al. (2006). Controlling as a management tool now (p. 279). Moscow: Audit UNITY Publisher.

Deming, E. (2011). Out of the crisis: A new paradigm of people management systems and processes (p. 419). Moscow: Alpina Publisher.

Egorshin, A. P. (2011). The organization of the personnel: The textbook (p. 320). Moscow: INFRA-M Publisher.

Falko, S. G., \& Nosov, V. M. (2005). Controlling the enterprise (p. 80). Moscow: Knowledge Russia Publisher.

Fayzullina, A. R. (2007). Immigration policy in modern Russia (federal and regional aspects) (Thesis for the degree of Candidate of Political Science. Ufa: Bashkir State University).

Fayzullina, A. R., \& Mukhametzyanova-Duggal, R. M. (2015). Multi-Confessional Societies in Russia and India: Models of Relations between the State and Religious Associations. Review of European Studies, 7(1), 12-17.

Fathutdinov, R. A. (2008). Strategic Marketing-One of the tooling competitiveness. Journal of Standards and Quality, 3, 60-62.

Folmut, H. I. (2005). Controlling Instruments from A to Z (p. 288). Moscow: Finance and Statistics Publisher.

Glischev, A. V. (2009). Quality, efficiency, morality (p. 358). Moscow: publishing Premium Engineering.

Gorbashko, E. A. (2008). Quality Management (p. 384). St. Petersburg: Piter.

Gumerov, A. V. et al (2015). The formation of the corporate structures development strategy based on the quality management methods. Journal of Asian Social Science, 1, 169-175.

Kaplan, R., D. N. (2005). The Balanced scorecard systems: From strategy to action (p. 304). Moscow: Olympus business publishing.

Karminsky, A. M. et al. (2005). Controlling in the business: Methodological and practical bases for the construction of controlling in organizations (p. 256). Moscow: Finance and Statistics Publisher.

Lavrentiev, V. A., \& Sharina, A. V. (2009). Intellectual potential of the enterprise: Concept, structure and direction of its development. Creative Economy, 2, 83-89.

Levina, E. Y., Saglam, F. A., Skorobogatova, A. I., Shaikhlislamov, A. Kh., Sagitova, V. R., \& Fayzullina, A. R. (2015). Quality Control Optimization of University Students Training. Asian Social Science, 11(2), 296-300.

Mahankova, T. P. (2010). The nature and evolution of concepts and views on human resources. In the world of scientific discovery, 1-2, 67-72. 
Mann, R., \& Mayer, E. (1995). Controlling for beginners (p. 208). Moscow: Finance and Statistics Publisher.

Masalimova, A. R. (2014). Traditional and modern model of corporate training mentors. Fundamental Research, $3(4), 830-836$.

Mayer, E. (2005). Controlling as a system of thought and control (p. 96). Moscow: Finance and Statistics Publisher.

Mikhailova, A. V. (2008). Development of personnel controlling the system of personnel management organization: Monograph (p. 196). Magnitogorsk State University Publisher.

Milner, B. Z. (2008). Organization theory (p. 453). Moscow: INFRA-M Publisher.

Muhamedyarov, A. M. (2008). Innovation Management (p. 176). Moscow: INFRA-M Publisher.

Noskova, M. V. (2010). The theoretical model of economic development category "human resources". Herald Altai State Agrarian University, 2, 89-93.

Petrenko, S. N. (2004). Controlling: Learning posobie (p. 328). Kazan Nick Center Publisher.

Porter, M. (1993). International competition (p. 896). Moscow: International relationship press.

Shaidullina, A. R. (2012). Regional Experience of Integration in System Vocational School-High School-Manufacture. Memoirs of Almetyevsk State Oil Institute, 2, 306-312.

Shigaev, A. I. (2008). Controlling development strategy (p. 351). Moscow: UNITY-DANA Publisher.

Volovikov, B. P., \& Rebrova, N. P. (2010). Systems approach to the formation of corporate strategies. Journal of Practical Marketing, 9, 32-36.

Webster, F. (2010). Pricing Strategy. Journal of Marketing and market research, 1, 21-37.

\section{Copyrights}

Copyright for this article is retained by the author(s), with first publication rights granted to the journal.

This is an open-access article distributed under the terms and conditions of the Creative Commons Attribution license (http://creativecommons.org/licenses/by/3.0/). 